\title{
A strategy for biosphere descriptions during site investigations for a repository of spent nuclear fuel
}

\author{
T. Lindborg ${ }^{1}$ and A. Löfgren ${ }^{2}$ \\ ${ }^{1}$ Swedish Nuclear Fuel and Waste Management Co., 10240 Stockholm, Sweden \\ ${ }^{2}$ A.E. Löfgren, Ivar Vidfamnes gata 29, 12652 Hägersten, Sweden
}

\begin{abstract}
Preceding the construction of a future repository of spent nuclear fuel, a descriptive ecosystem model has to be developed in order to meet the demands set by a safety assessment. The descriptive ecosystem model should be able to describe stocks and flows of matter, and processes that may affect these on a broad landscape scale. Here we describe the planned strategy to develop such a model in three steps; the conceptual model, introduction of site-specific data and, transfer and accumulation of matter in the landscape. The suggested method is based on an ecosystem approach using site-specific data. A mass balanced ecosystem model with food webs provide a way of analysing how matter are linked to different ecosystem components through fluxes. It is suggested that estimated inflow and outflow of matter in mass balanced ecosystem units will reduce the potential variation of transport and accumulation of matter by setting the physical and biological limits to the system. In this paper we present a strategy to build a descriptive ecosystem model and shows examples from the ongoing descriptions at Forsmark and Simpevarp in the Swedish site investigation programme to illustrate the ideas.
\end{abstract}

\section{INTRODUCTION}

During the next few years the Swedish Nuclear fuel and Waste Management Co. (SKB) performs site investigations at two sites in Sweden for a future repository of spent nuclear fuel. This paper describes the strategy for development of a descriptive ecosystem model and its use in the process of making a safety assessment for a repository. A safety assessment has to be able to predict and quantify dose to humans under different scenarios of radionuclide release. One of the approaches that the safety assessment will use, is an approach where transport and accumulation of radionuclides will be modeled by quantifying biogeochemical pathways of matter [1]. This work requires considerable knowledge about transport and accumulation of matter in the landscape. Here we present a strategy used by SKB to gather and build such a knowledge base that is based upon, in a site description context, novel methods using a system ecology perspective [2].

The descriptive ecosystem model should be able to describe processes and quantify patterns of importance for stock and flows of matter at the site. In order to put such a model together we have to identify the biotic and abiotic processes that are of central importance for our purpose. An exhaustive description of processes and interactions within an ecosystem important for a safety assessment was done within the SAFE project [3]. This description identified the processes that have to be further described and quantified e.g. in terms of transport or accumulation. It also describes interactions with other disciplines, such as the geology and hydrology. Moreover, the descriptive ecosystem model concerns not only present day conditions but also historical information. A historical perspective is of vital importance for understanding future landscape development e.g. human land use and land uplift due to glaciations. Historical information will therefore be an important key in predicting transport and accumulation of matter in a future landscape. 
This strategy is still under development and here we present the principle outline of the work and its state today.

\section{THE STRATEGY}

The strategy to build a descriptive ecosystem model can be described in the following three steps (fig. 1):

2.1 Building a general conceptual model that describes stocks and flows of matter, using functional organism groups where it is possible. This demands an effort of categorising the ecosystem into suitable units of resolution.

2.2 Collecting site specific data to adapt the conceptual model to the specific site resulting in a descriptive model describing stocks and flows of matter at the site for the suitable units of resolution. The data is presented in GIS.

2.3 Describing transfer and accumulation processes of matter within and between units in a spatially distributed landscape.

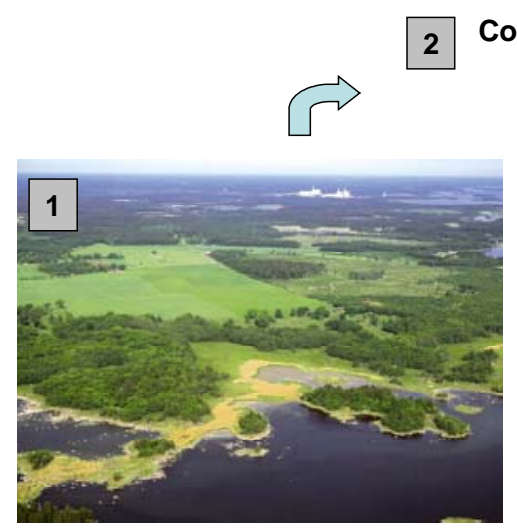

The site

Conceptual ecosystem model defining properties
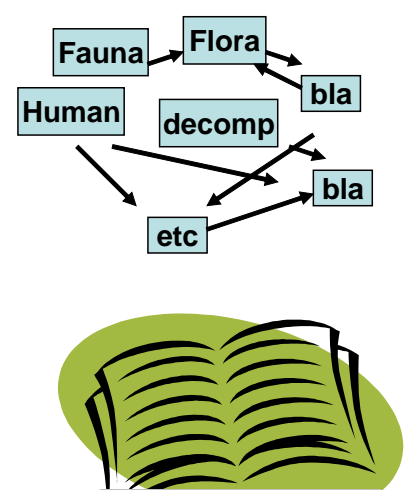

5. Site description

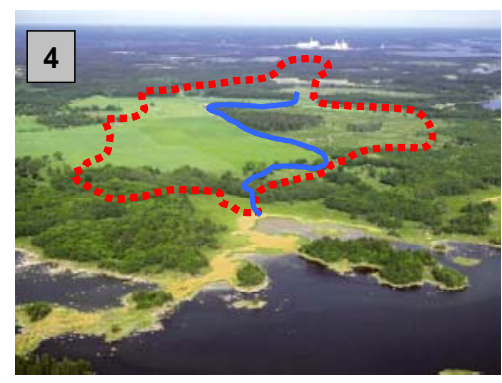

Flow and accumulation of matter

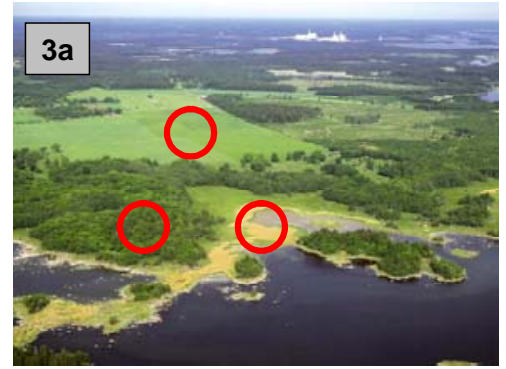

Sample collection of properties
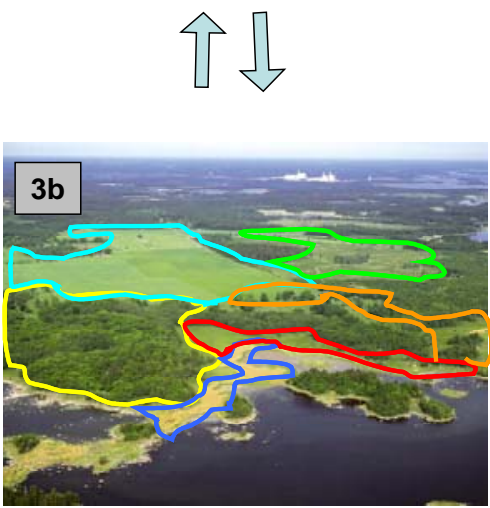

Property classification

Figure 1. The process of building a site descriptive ecosystem model. The site (1) is defined. A conceptual model (2) is produced that describes functional groups and the fluxes between them. Samples are collected at the site (3a) using quantitative statistics to describe the biotic and abiotic properties in the conceptual model. The landscape is divided into a number of distributed models using site data and GIS (3b). Flows and accumulation of matter are described using hydrological tools, drainage areas and site data (4). All the information is gathered into the site descriptive ecosystem model. 


\subsection{A conceptual model}

A conceptual model will be necessary as a starting point when identifying the different properties that affect the stocks and flows of matter in the ecosystem at the site (fig. 2). The model does not have to be site specific and is built upon literature and expertise knowledge for different fields of science [4]. This step will serve as the starting point for the planning of field surveys necessary for collecting the site-specific data in the next step (see 2.2 below). Another example of conceptual model is the work done by SKB at the SAFE site $[5,6]$.

The conceptual model could later, when site data are collected, be adjusted to a site specific conceptual model. This means that new information could be added or existing be taken away, i.e. the finding of a functional group needs to be considered or the biomass of another is too small to be relevant.

One of the more difficult tasks is to find a suitable categorization and classification of the landscape into "handy" units. First a large scale separation was done into terrestrial, limnic and marine ecosystems. Further classification was done using units as being a potential base for budget calculation of organic matter. The units are then further described using functional groups within the food web. The spatial resolution of the gathered data is of course context dependent. However, the resolution of the terrestrial landscape has in our case been a function of the resolution of satellite classification techniques and the diversity of major vegetation types. Similarly, the spatial resolution of lakes has been set by the possibilities to monitor each lake separately and the categorization of lake habitats is done using a recently developed classification system of habitats [7].

The budgets of organic matter in terrestrial systems are described by means of biomass, primary production, secondary production decomposition, mineralization and soil chemistry. The budgets of organic matter in lake and sea ecosystems are described by means of biomass, primary production, secondary production, decomposition and water chemistry [6]. The conceptual model should also identify and include those abiotic factors that are of importance for vertical or horizontal transport of matter, such as precipitation and ground water movement.

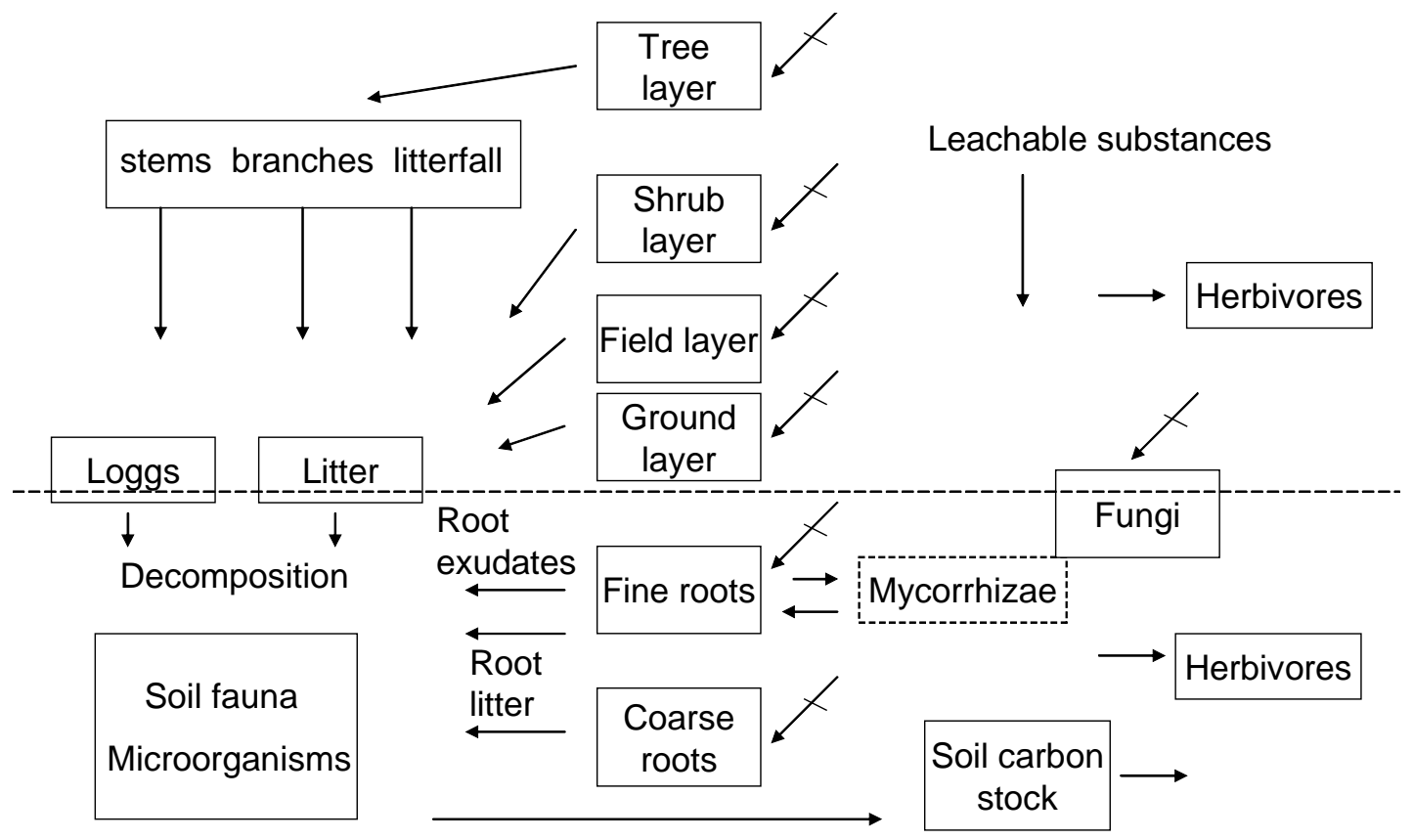

Figure 2. A conceptual model describing the stocks and flows of matter within a forest. Boxes illustrates stocks of matter, arrows fluxes of matter and crossed arrows are net primary production. 


\subsection{Site specific data}

The two sites in Sweden considered as potential sites for a future repository of spent nuclear fuel are both situated at the coast and do both include a large number of different ecosystems such as forests, agriculture land, wetlands, lakes and the sea. In this step we take the starting point from the conceptual model and uses site specific data to establish local budgets of standing stocks and flow of matter for the different units of resolution. The site-specific data is presented in GIS covering the specific area in a large database. This makes it possible to use over-layering techniques when merging data e.g. making spatial explicit estimates of standing organic matter from different functional groups such as tree layer, shrub layer, field layer and ground layer.

The resolution of the resulting GIS maps covering the terrestrial landscape is in our case set by the resolution of the satellite data used to classify the vegetation $(25 \mathrm{~m} \times 25 \mathrm{~m}$, SPOT4XI and Landsat satellites, [8]).

\subsection{Transfer and accumulation processes in the landscape}

Because of the relative constancy of carbon and energy contents of organic matter, carbon, energy, and biomass have been used interchangeable as currencies of the carbon and energy dynamics of ecosystems [9]. The proportions between carbon, nitrogen and phosphorous are often very constant within system, but differ between systems, e.g. terrestrial and limnic systems [10]. Matter is recycled between organisms in the food web and the physical environment within the ecosystem. Matter may also be accumulated within the terrestrial system, e.g. as peat. Accumulation often means that the matter leaves the recycling and that some kind of disturbance have to occur to release it to circulation again, e.g. human starts to plough old lake beds or harvest peat. However, matter is leaching from the terrestrial ecosystem into streams, following watercourses into lakes and in the end discharging into the sea. Some matter is accumulated along this way, e.g. in lake beds. In this step we want to construct a spatially explicit ecosystem model that will be able to describe these processes in the landscape.

The first step is to connect the different units by quantifying flows of matter between units within the ecosystem. Surface hydrology is considered to be the most important driving variable for transport and accumulation processes e.g. [11] and it will be subjected to quantitative modelling and simulation using site specific data in order to understand vertical and horizontal movement of surface water. The functional units of the landscape are defined by catchment areas that are constructed from water divides in the landscape (fig.3). This gives us a tool to separate or link different sub areas and ecosystem within the landscape. Moreover, it gives us, together with hydrology models the ability to calculate turnover time for any chosen part of the site.

The aquatic systems are important for transport but also for accumulation of matter in the lake or the sea bed. Budget calculations describing the flows of matter at the level of catchment area are done with hydrology and water chemistry, and will provide information concerning transport of matter into running water and lakes. By quantifying recharge and discharge it will be possible to quantify input and loss of matter in the lake. Calculations of matter transport in streams gives an estimation of the actual leakage from the terrestrial systems in their sub catchment areas. This makes it possible to validate estimated leakage and actual leakage from terrestrial systems. Consequently, there will be several possibilities to fine-tune the descriptive model in means of actual leakage of a number of chemical elements and substances into the running water using terrestrial information such as vegetation, soil type and size of the catchment area. Moreover, there will be possibilities to get estimates on what processes and indata that are most crucial in describing stocks and flows of matter.

The final recipient of the water together with transported matter is the sea where the water discharges, e.g. into a bay. Here we have an accumulation of transported matter and shallow bays may typically have a large production due to high nutrient availability. The bay also serves as the interface to the open sea through which a large exchange of matter may occur depending on water currents and hypsography. 
In the end will this model be turned into a numerical model using Tensit [12] to predict how and where matters are accumulated. During this step is the uncertainty of the model evaluated.

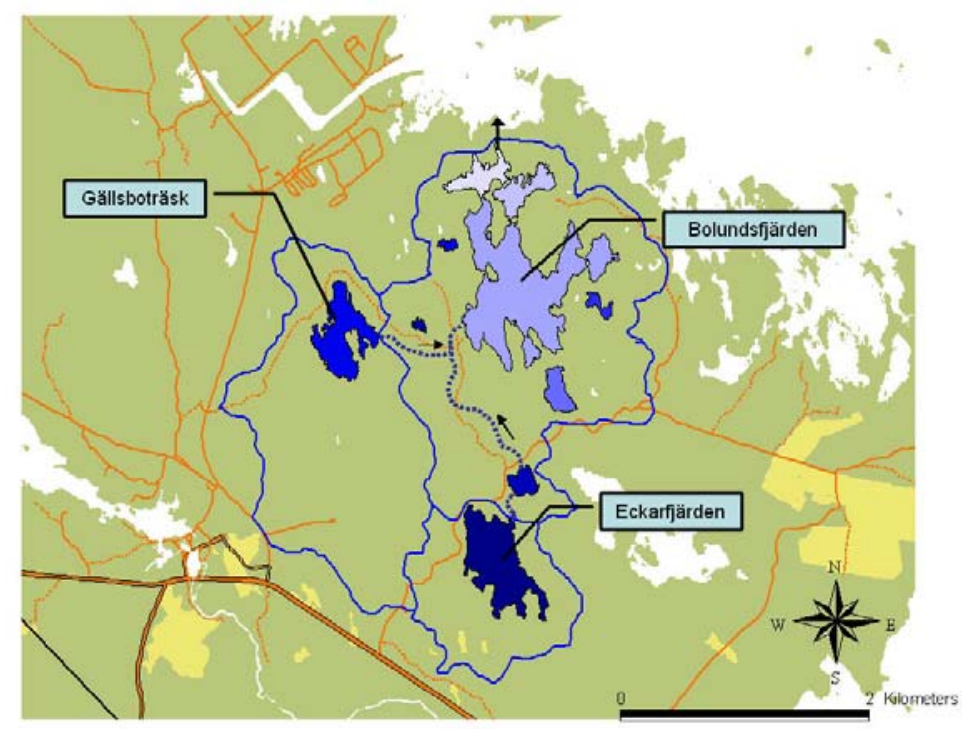

Figure 3. Examples of a model area in Forsmark. The drainage area Bolundsfjärden with the water sheds (blue lines) as the model boundary. Sub areas (Gällsboträsk and Eckarfjärden) are seen within the drainage area.

\section{DISCUSSION}

In risk assessment of radionuclides the focus has, until recently, been the protection of humans and thus the pathways leading to human consumption e.g. [13, 14]. Consequently ecological components have been omitted or incompletely described e.g. $[15,16]$. This approach has been increasingly questioned and new regulations require that effects on ecosystem should be considered e.g. [15, 17]. The suggested method is based on an ecosystem approach where ecosystems are delimited and described and later put together into a spatially explicit ecosystem model covering a landscape. This is a cross discipline work that incorporates a large number of disciplines. One of the great challenges will be to integrate all possibly data. During this integration a number of simplified assumptions have to be made. However, it will always be possible to backtrack the information in larger details if necessary due to the extensive site-specific database. This approach ensures that many of the simplifying assumptions made going from step 2 to 3 may be modelled and tested. A mass balanced ecosystem model with food webs provide a way of analysing how matter are linked to different ecosystem components through fluxes of e.g. carbon. The balance of nutrients required to support maximal growth for terrestrial plants is similar [18] and the nutrient that most strongly limits growth determines cycling rates of all nutrients. This element stoichiometry defines patterns of cycling of most nutrients in ecosystems [19]. It is thereby possible to establish quotients between important elements in e.g. the vegetation to facilitate mass calculations of other nutrients or radionuclides from established carbon masses. Moreover, by estimating inflow and outflow of matter in the ecosystem units will reduce the potential variation by setting the physical and biological limits for estimations of e.g. carbon accumulation in a lake bed. We therefore strongly believe that the ecosystem modelling approach combined with the use of site-specific data will result in more accurate and precise estimations of flow and accumulation of matter because of the site specific limitations that are introduced.

When we can describe standing stocks and flow of matter we will have a baseline for making predictions of dispersal and accumulation of chemical elements or substances, such as radionuclides, released in the area. Thereby providing the safety assessment with a tool to predict how and where 
radionuclides are transported and accumulated in the landscape making it possible to calculate potential does to humans at the specific site [20]. Adding the historical perspective on the landscape we will also be able to predict transport and accumulation of matter during succession and different management regimes.

\section{Acknowledgements}

The authors would like to thank Björn Söderbäck for commenting an earlier version of this manuscript.

\section{References}

[1] Anonymous. Interim main report of the safety assessment SR-Can. (TR-04-11, SKB, Stockholm, Sweden, 2004).

[2] Kumblad L., "The use of ecosystem modelling techniques in exposure assessments of radionuclides - an overview", In proceeding of the International Conference ECORAD, Aix-en-Provence, France, 2004, edited by XXXX (XXXX), p. XXX.

[3] Anonymous. Project SAFE - Scenario and system analysis. (R-01-13, SKB, Stockholm, Sweden, 2001).

[4] Löfgren A. and Lindborg T., A descriptive ecosystem model - a strategy for model development during site investigations. (R-03-06, SKB, Stockholm, Sweden, 2003) pp 113.

[5] Kumblad L. A transport and fate model of C-14 in a bay of the Baltic Sea at SFR: today and in future., (TR-01-15, SKB , Stockholm, Sweden 2001).

[6] Kumblad L, Gilek M, Næslund B and Kautsky U., Ecological Modelling 166 (2003) 193-210.

[7] Brydsten L., Carlsson T., Brunberg A. and Blomqvist P. A method for determination of morphometry, sediment distribution, and habitat diversity of lake basins and its application to three lakes in Uppland. (R-04-40, SKB, Stockholm, Sweden, 2004) pp. 35.

[8] Boresjö Bronge L. and Wester K., Vegetation mapping with satellite data of the Forsmark, Tierp and Oskarshamn regions. (P-03-83, SKB, Stockholm, Sweden, 2003) pp. 101.

[9] Chapin F, S., Matson P., Mooney H. A., Principles of Terrestrial Ecosystem Ecology. Springer -Verlag New York, Inc. 2002 pp 436.

[10] Elser J. J., Fagan W. F., Denno R. F. et al., Nature 408 (2000) 578-580.

[11] Blomqvist P, Brunberg A-K, Brydsten L, Lake and lake-related drainage area parameters for site investigation program. (R-00-38, SKB, Stockholm, Sweden, 2000) pp. 71.

[12] Jones J., Kautsky U., Vahllund C.F:, ” Tensit - A simulation tool for nuclide transport, risk and dose calculations" In proceeding of the International Conference ECORAD, Aix-en-Provence, France, 2004, edited by XXXX (XXXX), p. XXX.

[13] Strand P. and Larsson C-M., Delivering a framework for the protection of the environment from ionising radiation. In: Brechignac F., and Howard, B. J. (eds). Radioactive Pollutants, impacts on the environment. EDP Sciences, Les Ulis, 2001, pp 113-145.

[14] Copplestone D., Howard B. J. and Brechignac F. Journal of Environmental Radioactivity 74 (2004) 31-41.

[15] IAEA 1999. Critical groups and biospheres in the context of radioactive waste disposal. International Atomic Energy Agency. IAEA-TECDOC-1077, Vienna, Austria.

[16] Vieno T. and Nordman H., Safety asesment of spent fuel disposal in hästholmen, Kivetty, Olkiluoto and Romuvaara -TILA-)). POSIVA OY, POSIVA 99-07, Helsinki, Finland. 1999.

[17] SSI 1998. Regulations from Swedish Radiation Protection Institute concerning the safety of humans and the environment for the final repository of nuclear waste disposal. (In Swedish): Swedish Radiation Protection Institute (SSI). 1998:1, Stockholm, Sweden.

[18] Ingestad, T., Ågren, G. I. Physiologia Plantarum. 72 (1988) 450-459.

[19] Elser J. J., Urabe J., Ecology 80 (1999) 735-751.

[20] Kautsky U., Kumblad L., Lindborg T. and Jones J., ” Sr-Can Safety Assessment of a Repository for Spent Fuel - Cannister Performance and Effects on the Biosphere”, In proceeding of the International Conference ECORAD, Aix-en-Provence, France, 2004, edited by XXXX (XXXX), p. XXX. 